\title{
127. Factors Determining the Production of the Non-Diapause Eggs in the Silkworm.
}

\author{
By Soichi Fukuda. \\ Katakura Sericultural Experiment Station, Matsumoto. \\ (Comm. by Yô K. OKaDA, M.J.A., Nov. 12, 1951.)
}

When the eggs of the silkworm of a bivoltine race are incubated in the dark at a low temperature $\left(15^{\circ} \mathrm{C}\right)$, all the moths developed from these eggs lay the non-diapause eggs. It has been believed that the non-wintering property of the eggs is irrevocably determined and is never affected by changes of temperature and other environmental factors in the larval and pupal periods.

While studying the hormonic factors involved in the formation of the imago in the silkworm pupa, I have found that if the female pupae which have been determined to lay the non-diapause eggs after becoming the moths are decapitated immediately after pupation, many of the resultant moths lay the diapause eggs together with the non-diapause eggs or the diapause eggs alone (Fukuda, 1951). ${ }^{1)}$

The present paper deals with the further experiments destined to disclose the mechanism involved in the determination of voltinism in the silkworm.

\section{Experiments.}

The eggs of the moths of the Japanese bivoltine race which had mated with the males of the Chinese bivoltine race were incubated at $15 \pm 0.5^{\circ} \mathrm{C}$ in the dark. A.s soon as the larvae which had emerged from the eggs became fully grown and pupated, the pupae were ligatured with fine cotton thread at the level between the head and the thorax.

1. The organs removed by pupal decapitation and the eggs laid by the moths emerged from the operated pupae.

The headless moths developed from the operated pupae were dissected carefully after they finished laying the eggs. Many of the headless moths had neither the brain nor the suboesophageal ganglion. It should be mentioned, however, that a considerable number of the moths had both the organs intact but only dislocated from the normal site to the anterior end of the thorax. A few which were deprived of the brain only were also encountered.

1) Fukuda, S. (1951), Zool. Mag., 60, 119-121. 
The results of observations on the diapausing or non-diapausing properties of the eggs laid by the moths are summarized in Table 1, together with the results of dissection of the nervous system.

Table 1.

Results of dissection of the headless moths and the eggs laid by the moths.

\begin{tabular}{|c|c|c|c|c|}
\hline \multicolumn{2}{|c|}{$\begin{array}{l}\text { Results of dissection } \\
\text { of moths }\end{array}$} & \multirow{2}{*}{ No. of moths } & \multirow{2}{*}{$\begin{array}{l}\text { No. of moths } \\
\text { which laid } \\
\text { non-diapause } \\
\text { eggs alone }\end{array}$} & \multirow{2}{*}{$\begin{array}{l}\text { No. of moths which } \\
\text { laid diapause eggs } \\
\text { together with non- } \\
\text { diapause eggs or } \\
\text { diapause eggs alone }\end{array}$} \\
\hline Brain & $\begin{array}{l}\text { Suboeso- } \\
\text { phageal } \\
\text { ganglion }\end{array}$ & & & \\
\hline absent & absent & 119 & 2 & 117 \\
\hline absent & present & 2 & 0 & 2 \\
\hline present & present & 48 & 46 & 2 \\
\hline
\end{tabular}

As is shown in the table, the majority of the moths having neither the brain nor the suboesophageal ganglion laid the diapause eggs together with the non-diapause eggs or the diapause eggs alone. On the other hand, those carrying both of the ganglia always laid the non-diapause eggs alone. In these moths, however, the coalescence of the brain and the suboesophageal ganglion which normally would take place during the pupal period had generally been inhibited, and in some cases, the two kinds of ganglion were connected by slender oesophageal connectives like those of the larvae.

In two moths bearing both the brain and the suboesophageal ganglion in the thorax, the brain was found completely separated from the suboesophageal ganglion. It should be mentioned that these moths laid the diapause eggs besides the non-diapause eggs. Other two brainless moths having the suboesophageal ganglion only in the thorax laid both the diapause eggs and the non-diapause eggs.

\section{Transplantation of brain together with suboesophageal} ganglion.

Both the hosts and the donors were the 5th-stage female larvae developed from the eggs incubated at a low temperature in the dark. The complex of the brain and suboesophageal ganglion connected with the oesophageal connectives was grafted into the abdomen of the recipient larvae on the 2 nd or the 5 th day of the 5th stage. Immediately after the larvae became the pupae the head was removed by applying a ligature of cotton thread.

All of 21 moths emerged from the operated pupae laid the diapause eggs besides the non-diapause eggs or the diapause eggs alone 
in spite of the existence of the transplanted brain-suboesophageal ganglion complex in their abdomen.

\section{Transplantation of brain alone.}

In the way similar to the preceding experiment, the transplantations of the brain were performed in the female larvae on the 2nd or the 5th day of the 5th stage. Many of the resultant pupae were decapitated but some were left untouched.

Whereas all of 10 headless moths having the transplanted brain laid a number of diapause eggs, 15 moths emerged from the untouched pupae laid the non-diapause eggs alone.

\section{Transplantation of suboes phageal ganglion alone.}

As in the preceding experiments, the pupae bearing the transplanted suboesophageal ganglion in the abdomen were deprived of their own brain and suboesophageal ganglion by decapitation. Some of the pupae with the transplants were, however, left untouched and allowed to become the moths.

12 moths which emerged from the headless pupae with transplanted suboesophageal ganglion laid many diapause eggs. None of them laid the non-diapause eggs alone.

Of 12 moths emerging from the untouched pupae with grafted suboesophageal ganglion, three laid the non-diapause eggs alone, but nine laid the diapause eggs together with the non-diapause eggs or the diapause eggs alone.

\section{Transplantation of other cephalic organs.}

Transplantations of the corpora allata or of the frontal ganglion were also carried out in the 5th-stage larvae. The organs were always grafted together with the brain. The pupae having the grafts were decapitated. The headless moths which emerged from the experimental pupae laid the diapause eggs alone or together with the non-diapause eggs.")

\section{Discussion.}

If the pupae which have been determined to produce exclusively the non-diapause eggs are decapitated immediately after pupation, many of the resultant headless moths deprived of the brain or both the brain and the suboesophageal ganglion lay a number of diapause

2) In my unpublished experiments, it has been found that removal of the corpora allata in the silkworm larvae has no influence on the voltinism of the eggs to be laid by the moths in future. 
eggs. This suggests that the brain or the brain together with the suboesophageal ganglion of the pupae are involved in determining the diapausing or non-diapausing properties of the eggs. But the moths which emerged from the decapitated pupae carrying in the abdomen either the brain or the suboesophageal ganglion or both of them, also laid diapause eggs.

On the other hand, if the normal pupae receiving the suboesophageal ganglion as the transplant in the larval stage are allowed to develop, many of them become the moths which lay a number of diapause eggs. The production of the diapause eggs in these moths is thought to be due to the transplanted suboesophageal ganglion. It seems probable that a certain principle responsible for producing the diapause eggs is released from the grafts in the recipient pupae which is transmitted to the growing eggs and makes them the diapause eggs. ${ }^{\text {) }}$

Then, why do the moths deprived of their suboesophageal ganglion by decapitation lay the diapause eggs? At present, the question can not be answered satisfactorily. It may be possible that diapause factor is also produced by some other ganglia after separation from the brain.

It has been mentioned already that the headless moths with the suboesophageal ganglion but without the brain lay the diapause eggs. The brain was also removed surgically from a number of pupae immediately after pupation. Although the results are still meager on account of high mortality, all of 5 brainless moths obtained from the operated pupae laid the diapause eggs. These observations make it likely that the brain is of primary importance in the production of the non-diapause eggs.

But it should be recalled here that many of the eggs deposited by the headless moths having the brain isolated from the suboesophageal ganglion are the diapause eggs. Furthermore, the headless moths bearing the transplanted brain in the abdomen also laid many diapause eggs. When the pupae autotransplanted with the brain surgically removed soon after pupation become the moths, they also lay the diapause eggs (unpublished experiment). These experiments seem to indicate that the rôle of the brain in determining

3) The diapause of the silisworm eggs has hitherto been attributed to the existence of a hypothetical substance, designated the "inhibitory substance" (Watanabe, 1924), the "voltinism-determiner" (Umeya, 1926), the "hibernation substance" (Kogure, 1933) etc. The factor from the suboesophageal ganglion, for which I propose here the name "diapause factor" seems to be identical with this substance.

K. Hasegawa read before the annual meeting of the Sericultural Society of Japan in 1951 a paper on the suboesophageal ganglion as a possible source of the "inhibitory substance", but details of his experiments have not been presented. 
the non-diapausing property of the eggs is not of endocrinological nature.

The diapause factor seems to be produced or released from the suboesophageal ganglion and possibly also from some other ganglia. But as has been shown by the experiments presented above, its actual release takes place only when the connection between the brain and these ganglia is cut off. It is conceived therefore, that in the silkworm pupae determined to produce the non-diapause eggs the brain inhibits, by way of the oesophageal connectives, the suboesophageal ganglion to release the diapause factor.

The working hypothesis naturally assumes that in the silkworm larvae or pupae determined to produce the diapause eggs, ${ }^{4}$ the inhibitory action of the brain on the suboesophageal ganglion is annihilated and the latter organ is actively releasing the diapause factor. Experiments to ascertain this assumption are now under way.

\section{Summary.}

1. If the brain is removed immediately after pupation from the silkworm pupae which have been determined to produce the non-diapause eggs the resulting moths lay diapause eggs.

2. If isolated from the brain, the suboesophageal ganglion of the pupae releases a factor responsible for producing the diapause eggs. The "diapause factor" from the suboesophageal ganglion exerts a certain effect on the growing eggs and makes them the diapause eggs.

3. In the determination of the non-diapausing property of the eggs, the brain is of primary importance. It suppresses by way of the oesophageal connectives the suboesophageal ganglion to release the diapause factor.

4) If the silkworm eggs of a bivoltine race are incubated at a temperature above $25^{\circ} \mathrm{C}$ under illumination, all of the moths developed from the eggs lay diapause eggs alone. 